\title{
Isolation and characterization of lactic acid bacteria from human milk
}

\author{
Wenli Kang, ${ }^{1,2} \odot$ Lina Pan, ${ }^{2} \odot$ Can Peng, ${ }^{2} \odot$ Ling Dong, ${ }^{2} \odot$ Sufang Cao, ${ }^{2} \odot$ Haina Cheng, ${ }^{1}$ Yuguang Wang, ${ }^{1} \odot$

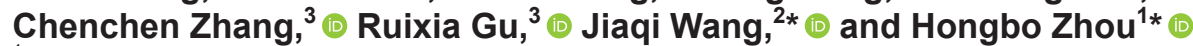 \\ ${ }^{1}$ School of Minerals Processing and Bioengineering, Central South University, Changsha 410083, Hunan, China \\ ${ }^{2}$ Ausnutria Institute of Food and Nutrition, Ausnutria Dairy (China) Co. Ltd., Changsha 410200, Hunan, China \\ ${ }^{3}$ College of Food Science and Technology, Yangzhou University, Yangzhou 225127, Jiangsu, China
}

\begin{abstract}
Human milk is the main source of nutrition for infants and the transmission of various microorganisms. The lactic acid bacteria (LAB) in breast milk allow for the establishment of the gut microflora of infants. In this study, we aimed to assess the probiotic potential of LAB strains isolated from breast milk of healthy Chinese women. Two strains, Lacticaseibacillus rhamnosus (formerly Lactobacillus rhamnosus) LHL6 and LHL7, were selected and identified through morphology observation, Gram staining, and 16S rDNA phylogenetic analysis. Using Limosilactobacillus fermentum (formerly Lactobacillus fermentum) CECT5716 as the standard reference strain, the screened strains were characterized for aspects of growth, production of lactic acid and $\mathrm{H}_{2} \mathrm{O}_{2}$, antibiotic susceptibility, survival under simulated gastrointestinal conditions, and tolerance to cadmium (Cd). In de Man, Rogosa, and Sharpe (MRS) broth, LHL6 and LHL7 showed longer lag phases than CECT5716 but higher specific growth rates. For the production of lactic acid and $\mathrm{H}_{2} \mathrm{O}_{2}$, LHL7 performed better than LHL6 and CECT5716, indicating better antimicrobial ability. Strain LHL7 generated $9.99 \mathrm{mg} / \mathrm{L}$ $\mathrm{H}_{2} \mathrm{O}_{2}$, considerably higher than $1.25 \mathrm{mg} / \mathrm{L}$ for LHL6 and $2.33 \mathrm{mg} / \mathrm{L}$ for CECT5716. According to European Food Safety Authority minimum inhibitory concentrations, all of the investigated strains were resistant to chloramphenicol, streptomycin, and kanamycin. However, unlike LHL6 and CECT5716, LHL7 was susceptible to ampicillin and resistant to tetracycline. Resistance to azithromycin, cephalexin, and penicillin $\mathrm{G}$ were similar for all 3 strains, whereas CECT5716 was resistant to a higher concentration of roxithromycin. All 3 strains were able to survive in a simulated gastric-like solu-
\end{abstract}

Received April 12, 2020.

Accepted July 7, 2020.

*Corresponding authors: jiaqi.wang@ausnutria.com and zhouhb@ csu.edu.cn tion, but a low percentage survived in the presence of $0.4 \%$ bile salt and $7 \%$ pancreatin. Encapsulation with protectants may enhance the survival rate. All 3 strains were tolerant to $500 \mathrm{mg} / \mathrm{L} \mathrm{Cd}$ in MRS broth and to $1,000 \mathrm{mg} / \mathrm{L} \mathrm{Cd}$ on MRS agar medium. In summary, 2 novel strains of LAB were obtained that have similar characteristics to the reference strain CECT5716. This work identified potential probiotic candidates for application in the food and pharmaceutical industries and facilitated identification of further probiotics.

Key words: lactic acid bacteria, human milk, isolation/ identification, characterization

\section{INTRODUCTION}

Since the beginning of the 21st century, studies on the human milk microbiome have attracted researchers worldwide. Bacterial families common in human milk include Streptococcaceae, Pseudomonadaceae, Staphylococcaceae, Lactobacillaceae, and Oxalobacteraceae (Li et al., 2017; Moossavi and Azad, 2019). The existence of microbes distinguishes human milk from infant formula, which contains the most relevant postnatal elements for infant's health. Differences in the composition and activity of gut microbiota between breast-fed and formula-fed infants have been widely reported (Guaraldi and Salvatori, 2012; Ojo-Okunola et al., 2018; Liu et al., 2020b). Particularly, breast-fed infants have a reduced risk of infectious diseases, such as diarrhea, diabetes, allergies, and asthma (Guaraldi and Salvatori, 2012; Azad et al., 2013; Mueller et al., 2015). Reports have speculated the transmission of probiotic bacteria from the mothers to their infants via breast milk (Pannaraj et al., 2017; Williams et al., 2019).

Human milk has been shown to be a good source of probiotics because the bacteria would fulfill some of the main criteria generally recommended for human probiotics, such as human origin, adaptation to dairy substrates, and a history of safe, prolonged intake by infants (Martín et al., 2003). Several strains originating from human milk have been used as probiotics (Mc- 
Guire and McGuire, 2015). For instance, Limosilactobacillus fermentum (formerly Lactobacillus fermentum) CECT5716, isolated from the breast milk of a Spanish mother, has been approved for use in baby food by the National Health Commission of the People's Republic of China in 2016 (Martín et al., 2005; GilCampos et al., 2012; NHC-PRC, 2016). Nevertheless, geographic location and dietary pattern may seriously affect human milk microbiota profiles (Boix-Amorós et al., 2019; Oikonomou et al., 2020; Zimmermann and Curtis, 2020). Thus, native probiotic strains might be more suitable for Chinese people than strains from other locations. Intellectual property rights belonging to China will also facilitate the utilization of probiotics by Chinese people. Several potential probiotic strains from Chinese human milk have been isolated (Jiang et al., 2016; Gao et al., 2017; Liu et al., 2020a); for example, Lacticaseibacillus rhamnosus (formerly Lactobacillus rhamnosus) SHA113 (Riaz Rajoka et al., 2017; Li et al., 2020) but not yet authorized for application as food for humans. Therefore, increased research efforts in this field are needed.

A set of in vitro tests have been reported for the screening and identification of potential probiotic bacteria from human milk (Martín et al., 2005; Langa et al., 2012; Liu et al., 2020a). Of importance is the tolerance to gastrointestinal tract (GIT) conditions, which may affect their survival ability in vivo (Riaz Rajoka et al., 2017). Production of antimicrobial compounds, such as $\mathrm{H}_{2} \mathrm{O}_{2}$ and lactic acid, is important for the prevention of infectious diseases inside the host (Martín et al., 2005). Antibiotic resistance is also an essential criterion for the screening and selection of probiotics (Jose et al., 2015). Studies have revealed that antibiotic resistance genes can be transferred to other bacteria in vivo (Lavilla-Lerma et al., 2013; Huddleston, 2014). Finally, the growth characteristics of a strain are important for industrial production and application. For example, heavy metal tolerance and binding capability have become a new target for the selection of probiotics, because heavy metals can cause health problems in both humans and animals via contamination of food. Some LAB strains in connection with heavy metals have been isolated, including Lactiplantibacillus plantarum ssp. plantarum (formerly Lactobacillus plantarum), Lacticaseibacillus rhamnosus, and Bifidobacterium lactis (Matyar et al., 2008; Zhai et al., 2015; Yin et al., 2016).

The objective of this study was to isolate LAB strains from breast milk of healthy Chinese women and to estimate their potential as probiotics using a series of in vitro tests, such as growth curves, lactic acid production, $\mathrm{H}_{2} \mathrm{O}_{2}$ production, antibiotic resistance, survival under simulated GIT conditions, and tolerance to the heavy metal cadmium.

\section{MATERIALS AND METHODS}

\section{Isolation and Identification}

Written informed consent was obtained from mothers who provided breast milk samples for this study (Medical Ethics Committee of Xiangya School of Public Health, Central South University, China). A total of 12 samples were obtained from 9 women (some donated more than once). All volunteers were ethnic Han Chinese and were born and grew up in Hunan, China. Samples were collected using a sterile breast pump device after a thorough cleaning of the nipple and surrounding area with sterile water. The first drops of milk were discarded. Immediately after collection, samples were directly poured on de Man, Rogosa, and Sharpe (MRS) agar plates (Oxoid, Basingstoke, UK) containing $1.0 \% \mathrm{CaCO}_{3}(\mathrm{wt} / \mathrm{vol})$ at the side of an alcohol lamp to minimize contamination. The plates were then sealed with parafilm and anaerobically incubated at $37^{\circ} \mathrm{C}$ for $48 \mathrm{~h}$ inside rectangular jars with AnaeroPack and Anaero-indicator (AnaeroPack, Mitsubishi Gas Chemical America Inc., New York, NY). Single colonies that generated a surrounding clear zone were selected and identified using Gram staining and microscopic observation. Twenty-five strains were isolated in total and identified by the volunteer's initials; numbers in the strain name refer to different isolates. To test catalase activity, a droplet of $3 \% \mathrm{H}_{2} \mathrm{O}_{2}$ was mixed with a single colony using an inoculating needle; a lack of bubbles indicated a negative result (Liu et al., 2020a). Species identification of the isolates was performed by phylogenetic analysis based on the sequences of $16 \mathrm{~S}$ rDNA (Liu et al., 2020a); Limosilactobacillus fermentum CECT5716, which was purified from commercial probiotics (Hereditum, Biosearch Life, Biosearch, Granada, Spain), was used as the reference strain. Total genomic DNA was extracted using the Rapid Bacterial Genomic DNA Isolation Kit (Sangon Biotech, Shanghai, China) and amplified via PCR using primers of 27F (5'-AGAGTTTGATCCTGGCTCAG-3') and 1492R (5'- TACGGCTACCTTGTTACGACTT- $\left.{ }^{\prime}\right)$. The PCR products were sequenced by Tsingke Bio (Hunan, China) and compared with the National Center for Biotechnology Information BLAST sequence database (https://blast.ncbi.nlm.nih.gov/Blast.cgi) to identify the strains (Ding et al., 2017).

\section{Growth Curve}

A growth curve of the strains in MRS broth was constructed using MRS broth as control. First, $50-\mu \mathrm{L}$ cultures at mid-exponential phase were inoculated into $10 \mathrm{~mL}$ of MRS broth and cultured at $37^{\circ} \mathrm{C}$. Cell density 
was measured spectrophotometrically as the optical density at $600 \mathrm{~nm}\left(\mathbf{O D}_{600 \mathrm{~nm}}\right)$ at approximately 3 -h intervals until the stationary phase was reached. The growth curve was constructed with time on the x-axis and $\mathrm{OD}_{600 \mathrm{~nm}}$ on the y-axis. The specific growth rate $(\mu$, $\mathrm{h}^{-1}$ ) was calculated according to Eq. [1], where $t$ is time (h) and $N$ is $\mathrm{OD}_{600 \mathrm{~nm}}$. The maximum specific growth rate $\left(\mu_{\max }\right)$ was obtained from the curve of $\mu$ versus $t$ :

$$
\mu=\frac{\ln N_{t}-\ln N_{t-1}}{\Delta t}
$$

\section{Lactic Acid Production}

Two types of media were used to evaluate lactic acid production by the LAB strains to determine their performance in less nutritious (GYE) and nutritious conditions (MRS). The first was distilled water containing $1 \%$ (wt/vol) glucose and 1\% (wt/vol) yeast extract (GYE), and the second was MRS broth. Overnight cultures were inoculated in both media at an inoculum of $1 \%$ ( $\mathrm{vol} / \mathrm{vol}$ ). The $\mathrm{pH}$ of cultures was measured using a digital $\mathrm{pH}$ meter (Mettler Toledo, Zurich, Switzerland) after a 66 -h culture at $37^{\circ} \mathrm{C}$. The acidity was determined by titration with $0.1 \mathrm{M} \mathrm{NaOH}$ solution according to AOAC method 947.05 (AOAC, 1990), where $2 \mathrm{~mL}$ of each sample was diluted in $25 \mathrm{~mL}$ of distilled water (Wang et al., 2019; Jiang et al., 2020). The end point of titration was set at $\mathrm{pH} 7.0$ instead of using an indicator. Lactic acid production was calculated according to Wang et al. (2019).

\section{$\mathrm{H}_{2} \mathrm{O}_{2}$ Production}

The concentration of $\mathrm{H}_{2} \mathrm{O}_{2}$ in the supernatants was measured by using the method of Martín et al. (2005), with modifications. First, MRS broth was inoculated with $1 \%$ overnight culture and incubated at $37^{\circ} \mathrm{C}$ for 24 h. Nine milliliters of culture was centrifuged at 12,000 $\times g$ for $20 \mathrm{~min}$ at $4^{\circ} \mathrm{C}$. The cells were harvested, washed twice with $50 \mathrm{~m} M \mathrm{PBS}$ (pH 6.0), and then resuspended in $9 \mathrm{~mL}$ of the same PBS supplemented with $5 \mathrm{mM}$ glucose. Then, $0.5 \mathrm{~mL}$ of this mixture was transferred to $9.5 \mathrm{~mL}$ of PBS containing glucose and incubated aerobically for $24 \mathrm{~h}$ at $37^{\circ} \mathrm{C}$. The supernatants were assayed for $\mathrm{H}_{2} \mathrm{O}_{2}$ after centrifugation at $12,000 \times g$ for $20 \mathrm{~min}$ at $4^{\circ} \mathrm{C}$. Then, $1 \mathrm{~mL}$ of horseradish peroxidase solution $(0.01 \mathrm{mg} / \mathrm{mL})$ and $0.1 \mathrm{~mL}$ of tetramethylbenzidinemethanol solution $(2.5 \mu \mathrm{g} / \mathrm{mL})$ were added to $5 \mathrm{~mL}$ of the supernatant. The tubes were incubated for $10 \mathrm{~min}$ at $37^{\circ} \mathrm{C}$. Then, $0.2 \mathrm{~mL}$ of $4 \mathrm{~N} \mathrm{HCl}$ was added to stop the reaction. The absorbance was measured at $400 \mathrm{~nm}$. Concentrations of $\mathrm{H}_{2} \mathrm{O}_{2}$ were determined by comparing with the values of the standard curve generated under identical conditions (Gilliland, 1969).

\section{Antibiotic Susceptibility Assay}

Nine commonly used antibiotics were tested in this assay, including azithromycin, cephalexin, ampicillin, penicillin G, tetracycline, roxithromycin, chloramphenicol, streptomycin, and kanamycin. Stock solutions (8 $\mathrm{g} / \mathrm{L}$ ) were sterilized with $0.22-\mu \mathrm{m}$ pore diameter filters, and stored at $-20^{\circ} \mathrm{C}$ for no more than 1 mo. Suitable solvents were chosen for different antibiotics (Table 1). Final concentrations of the antibiotics in MRS broth were adjusted to $0.64,1.28,2.48,4.8,9.6,20$, $40,80,160,320,640$, and $1,280 \mathrm{mg} / \mathrm{L}$. Then, $1 \%$ (vol/ vol) overnight bacterial cultures were inoculated and cultured for $16 \mathrm{~h}$ at $37^{\circ} \mathrm{C}$. Cultures without inoculum were set as blanks and those without antibiotics were set as positive controls. The $\mathrm{OD}_{600 \mathrm{~nm}}$ was measured and analyzed. The MIC refers to the lowest antibiotic concentration at which there was no obvious bacterial growth (Charteris et al., 1998; Martín et al., 2005).

\section{Survival Under Simulated GIT Conditions}

The survival of LAB when they were delivered through fermented formula milk was tested (Marteau et al., 1997; Martín et al., 2005). Eurence formula milk was provided by Ausnutria Dairy (China) Co. Ltd. (Changsha, Hunan, China). Fermented milks containing $\sim 10^{9} \mathrm{cfu} / \mathrm{mL}$ of LAB were prepared (Marteau et al., 1997). To simulate in vivo dilution by saliva, 30 $\mathrm{mL}$ of fermented milk was well mixed with $5 \mathrm{~mL}$ of a saliva-simulant solution, which was composed of 6.2 $\mathrm{g} / \mathrm{L} \mathrm{NaCl}, 2.2 \mathrm{~g} / \mathrm{L} \mathrm{KCl}, 0.22 \mathrm{~g} / \mathrm{L} \mathrm{CaCl}_{2}$, and $1.2 \mathrm{~g} / \mathrm{L}$ $\mathrm{NaHCO}_{3}$. Subsequently, $5 \mathrm{~mL}$ of a solution intended to mimic gastric juice was added $(2.1 \mathrm{~g} / \mathrm{L} \mathrm{NaCl}$ and $0.802 \mathrm{~g} / \mathrm{L}$ pepsin, $\mathrm{pH}=5.0$, pepsin activity $370 \mathrm{U} /$ $\mathrm{mL}$ ). The mixture was incubated at $37^{\circ} \mathrm{C}$ with agitation. The $\mathrm{pH}$ was successively adjusted by adding 4 $N \mathrm{HCl}$ to reproduce the values found in humans after yogurt consumption: $\mathrm{pH} 5.0$ at initiation, $\mathrm{pH} 3.0$ at

Table 1. The solvents used for 9 antibiotics

\begin{tabular}{ll}
\hline Antibiotic & Solvent \\
\hline Azithromycin & Distilled water \\
Cephalexin & Distilled water \\
Ampicillin sodium & Distilled water \\
Penicillin G & Phosphate buffer, pH 6.0 \\
Tetracycline & Phosphate buffer, pH 4.5 \\
Roxithromycin & Ethanol followed by distilled water \\
Chloramphenicol & Ethanol followed by distilled water \\
Streptomycin & Distilled water \\
Kanamycin & Distilled water \\
\hline
\end{tabular}


$40 \mathrm{~min}, \mathrm{pH} 2.0$ at $60 \mathrm{~min}$, and $\mathrm{pH} 1.8$ after $80 \mathrm{~min}$ for a duration of $100 \mathrm{~min}$. Samples were taken at 40, 60,80 , and $180 \mathrm{~min}$. The $\mathrm{pH}$ was then adjusted to 6.5 \pm 0.2 by adding $1 \mathrm{M} \mathrm{NaHCO}_{3}$. Ten $\mathrm{mL}$ of simulated duodenal fluid was introduced, which contained $5 \mathrm{~g} / \mathrm{L}$ $\mathrm{NaCl}, 0.6 \mathrm{~g} / \mathrm{L} \mathrm{KCl}, 0.25 \mathrm{~g} / \mathrm{L} \mathrm{CaCl} 2,0.4 \%$ bile salt, and $7 \%$ pancreatin (Rubio, Hefei Bomei Biotechnology Co. Ltd., Hefei, China). Two hours later, the last sample was taken. All of the samples underwent serial 10-fold dilution with sterile saline immediately after the collection. One milliliter of each dilution was poured onto MRS agar plates and evenly distributed by shaking. An aerobic incubation at $37^{\circ} \mathrm{C}$ for $48 \mathrm{~h}$ was carried out for the determination of bacterial survival. The survival rate was calculated according to Zhai et al. (2015).

\section{Bacterial Tolerance to Cadmium}

The MIC approach was applied to the determination of Cd tolerance (Abou-Shanab et al., 2007). A sterile solution of cadmium sulfate (Sigma-Aldrich, Steinheim, Germany) was obtained by filtering through $0.22-\mu \mathrm{m}$ pore size filters. The filtrates were added to MRS agar medium to obtain $\mathrm{Cd}$ concentrations of 5, 10, 50, 100, 200, 500, and 1,000 mg/L. Every agar plate was subdivided into 4 equal sectors, and a loop of overnight culture was spotted on each sector, reserving one as a blank. The growth of bacteria was recorded after an incubation of $48 \mathrm{~h}$ at $37^{\circ} \mathrm{C}$. The MIC was defined as the lowest $\mathrm{Cd}$ concentration at which the growth of LAB was completely inhibited. Then, MRS broth, containing serial concentrations of $\mathrm{Cd}$, including $5,10,50,100$, $200,500,1,000$, and $2,000 \mathrm{mg} / \mathrm{L}$, was inoculated with $1 \%$ overnight cultures. The tubes were cultured at $37^{\circ} \mathrm{C}$ for $20 \mathrm{~h}$. Absorbance at $600 \mathrm{~nm}$ were measured using a microplate reader (Epoch, Biotek, America).

\section{Cd Binding Assay}

Cadmium binding ability of the 3 strains was analyzed as described previously (Zhai et al., 2015) with minor modifications. The strains were incubated for 20 $\mathrm{h}$ at $37^{\circ} \mathrm{C}$. Pellets of the $10-\mathrm{mL}$ cultures were harvested by centrifugation at $12,000 \times g$ for $20 \mathrm{~min}$ and doublewashed with ultrapure water. The wet weight of cell pellets was used to calculate the cell concentration. Then, a suitable volume of culture was centrifuged as above. Pellets were washed in the same manner and resuspended in cadmium sulfate solutions containing $50 \mathrm{mg} / \mathrm{L} \mathrm{Cd}$ to obtain a final bacterial concentration of $1 \mathrm{~g} / \mathrm{L}$ (wet weight). The $\mathrm{pH}$ of the suspension was immediately adjusted to $6.0 \pm 0.2$ with dilute $\mathrm{NaOH}$ or $\mathrm{HNO}_{3}$. The tubes were incubated at $37^{\circ} \mathrm{C}$ for $1 \mathrm{~h}$ and then centrifuged for $20 \mathrm{~min}$ at $8,000 \times g$. The supernatant was collected for the determination of residual Cd concentration by a Spectroblue inductively coupled plasma optical emission spectrometer (ICP-OES, FMX 26, Spectro, Kleve, Germany). The percent of Cd removed by the bacteria was considered the $\mathrm{Cd}$ binding ability and expressed as follows:

$$
\operatorname{Removal}(\%)=\frac{C_{0}-C_{1}}{C_{0}} \times 100 \%,
$$

in which $C_{0}$ and $C_{1}$ are the initial and residual concentrations of $\mathrm{Cd}$, respectively.

\section{Statistical Analysis}

Technological experiments were carried out in triplicate for each assay. All data were expressed as mean \pm standard deviation. Results were considered significant at $P<0.05$.

\section{RESULTS AND DISCUSSION}

\section{Isolation and Identification}

Two strains, LHL6 and LHL7, were screened from 25 isolates for further evaluation based on their performance on MRS agar plates containing $\mathrm{CaCO}_{3}$. In the assay, LHL6 and LHL7 showed the largest clearing zones; isolation was carried out based on the appearance of LAB and the clearing zone around the colony on MRS agar plates supplemented with $1 \% \mathrm{CaCO}_{3}$. Under the microscope, bacteria were characterized as rod-shaped and gram-positive (Figure 1). For catalase activity, all the strains were negative (no bubbles were observed). Based on the results of $16 \mathrm{~S}$ rDNA sequencing, LHL6 had high sequence identity (99.86\%) to Lacticaseibacillus rhamnosus strain ZZ8\#4, and LHL7 had high sequence identity (99.93\%) to Lacticaseibacillus rhamnosus strain TSP-LRh1. A phylogenetic tree was constructed (Figure 2) with $16 \mathrm{~S}$ rDNA sequences and demonstrated that the selected strains belonged to Lacticaseibacillus rhamnosus and that the reference strain CECT5716 was a member of Limosilactobacillus fermentum.

\section{Growth Curve}

Growth curves of the LHL6, LHL7, and CECT5716 strains in MRS broth were constructed using sterile MRS medium as control, and the specific growth rate was calculated (Figure 3). As can be seen in Figure 3A, the lag phase of LHL6, LHL7, and CECT5716 lasted 
10,12 , and $6 \mathrm{~h}$, respectively. This phenomenon indicated rapid adaptation of CECT5716 to the tested condition. Good adaptation capability can help bacteria adapt to different environments, which might improve probiotic function in the gut. However, CECT5716 grew much more slowly, reaching the stationary phase $44 \mathrm{~h}$ after inoculation, with a final $\mathrm{OD}_{600 \mathrm{~nm}}$ of 0.639 , whereas LHL6 reached an $\mathrm{OD}_{600 \mathrm{~nm}}$ of 0.964 in $27 \mathrm{~h}$. The logarithmic period of LHL7 started after $14 \mathrm{~h}$ and thereafter reached 0.673 at $30 \mathrm{~h}$.

As shown in Figure 3B, the maximum specific growth rates of LHL6 and LHL7 in MRS broth at $37^{\circ} \mathrm{C}$ were 0.307 and $0.215 \mathrm{~h}^{-1}$, respectively, values 3 and 2 times higher than that of CECT5716 $\left(0.072 \mathrm{~h}^{-1}\right)$. A large quantity of cells or byproducts could be generated by these strains when cultured under specific, controlled conditions with adequate nutrient supply (Kuznetsov et al., 2017). Nevertheless, the growth performance of the strains in this study was under optimal conditions (in MRS broth, at $37^{\circ} \mathrm{C}, \mathrm{pH} 6.2$ ), which is different from growth in the gut or that under industrial production conditions. Thus, further studies need to be carried out to evaluate the strains under different conditions of use.

\section{Production of Lactic Acid and $\mathrm{H}_{2} \mathrm{O}_{2}$}

The LAB have long been considered the primary microbiological barrier to pathogenic infection through their production of antimicrobial compounds, such as lactic acid, $\mathrm{H}_{2} \mathrm{O}_{2}$, or bacteriocin (Martín et al., 2005). Here, we estimated the production of lactic acid and $\mathrm{H}_{2} \mathrm{O}_{2}$ by the selected strains.

Lactic acid production by the 3 strains in MRS broth and GYE medium, along with the $\mathrm{pH}$ of the cultures, is presented in Figure 4. Strains LHL6 and LHL7 exhibited higher culture pH than CECT5716 in GYE medium but a lower $\mathrm{pH}$ in MRS broth. The lactic acid production of LHL6 and LHL7 was 8.40 and $17.34 \mathrm{mg} / 100 \mathrm{~mL}$ in GYE medium, respectively, which was lower than that of CECT5716 $(20.34 \mathrm{mg} / 100 \mathrm{~mL})$.

Greater lactic acid production for all 3 strains was detected in MRS broth compared with GYE medium. The lactic acid yield for LHL6 and LHL7 was 70.29 and $65.43 \mathrm{mg} / 100 \mathrm{~mL}$, respectively, in MRS broth at $\mathrm{pH} 3.8$, whereas that of CECT5716 was $32.31 \mathrm{mg} / 100$ $\mathrm{mL}$. The fact that $50 \%$ more lactic acid was produced by CECT5716 cultured in MRS at pH 4.5 than in GYE culture at $\mathrm{pH} 3.7$ indicated that more acid chemicals could be obtained in MRS broth than in GYE medium. Cell density was measured simultaneously (data not shown) and was higher in MRS, which might explain why more lactic acid was produced when strains were cultured in MRS. Even in the GYE medium, which consists of only glucose and yeast extract as nutrients, the LHL7 strain could produce almost the same amount of lactic acid as the CECT5716 strain. Lactic acid is one of the main antimicrobial compounds for LAB to compete with other microorganisms (Martín et al., 2005), particularly pathogenic microbes, so good lactic acid production supports the potential use as probiotics.

All the tested LAB strains were positive for $\mathrm{H}_{2} \mathrm{O}_{2}$ production (Figure $4 \mathrm{C}$ ). The amounts of $\mathrm{H}_{2} \mathrm{O}_{2}$ were assessed after $20 \mathrm{~h}$ of culture at $37^{\circ} \mathrm{C}$. The LHL7 strain produced $9.99 \mathrm{mg}$ of $\mathrm{H}_{2} \mathrm{O}_{2} / \mathrm{L}$ of culture, considerably higher than the other 2 strains $(1.25 \mathrm{mg} / \mathrm{L}$ for LHL6 and $2.33 \mathrm{mg} / \mathrm{L}$ for CECT5716). This also illustrated the stronger competitive ability of LHL7 against pathogens, which represented $40 \%$ higher $\mathrm{H}_{2} \mathrm{O}_{2}$ production than Lactobacillus gasseri CECT5715 and Lactobacillus gasseri CECT5714 (Martín et al., 2005).

For the production of either lactic acid or $\mathrm{H}_{2} \mathrm{O}_{2}$, the LHL7 strain showed better ability than either LHL6
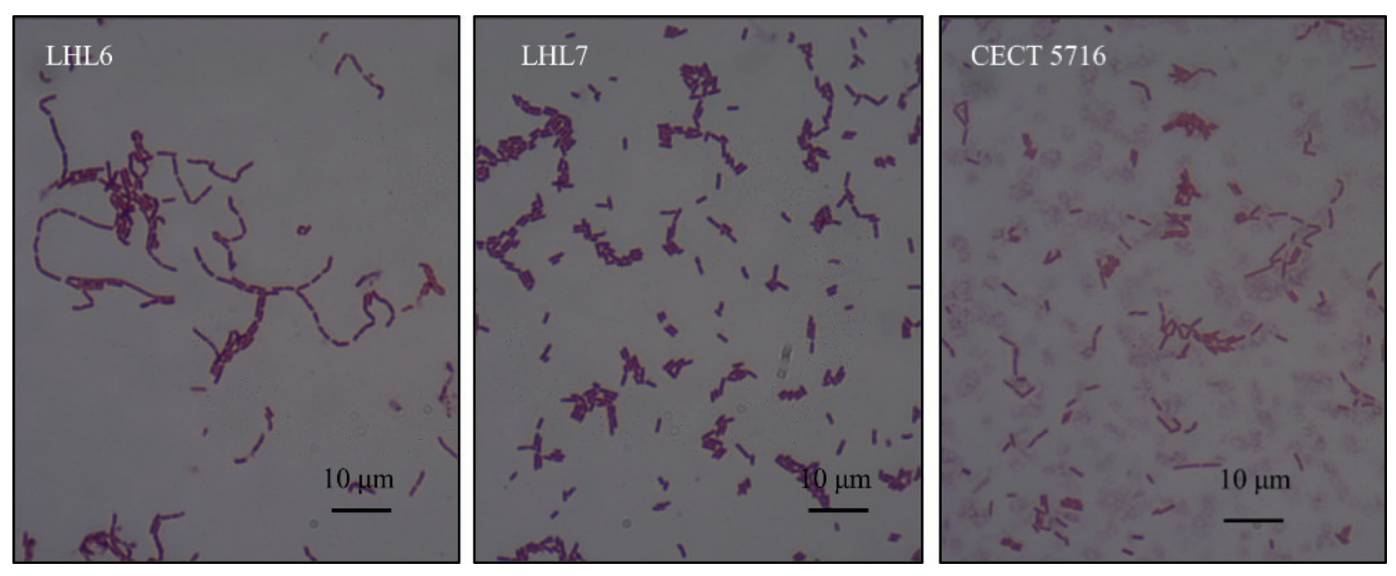

Figure 1. Micrographs of Gram-stained cells of Lacticaseibacillus rhamnosus LHL6, Lacticaseibacillus rhamnosus LHL7, and Limosilactobacillus fermentum CECT5716. Scale bar $=10 \mu \mathrm{m}$. 


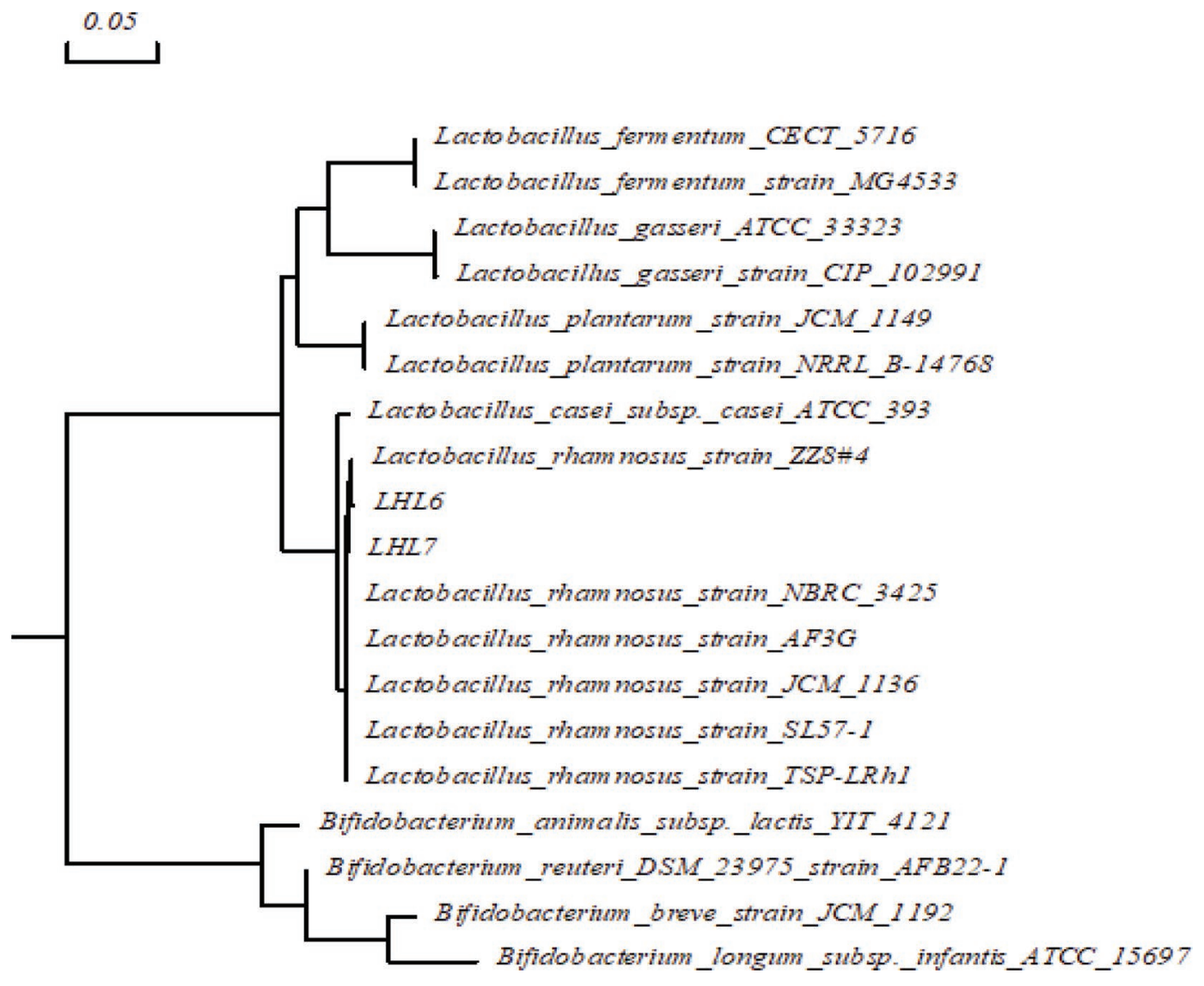

Figure 2. Phylogenetic tree of strains LHL6, LHL7, and Lactobacillus fermentum CECT5716 based on 16S rDNA gene sequences.

or CECT5716, indicating good potential as a human probiotic that competes with other microorganisms.

\section{Antibiotic Susceptibility}

Antibiotic sensitivity is considered an important part of the safety assessment of probiotics. The disc antibiotic susceptibility method is generally preferred. However, probiotic cells are exposed to a near-liquid environment after oral administration, such as saliva, gastric juice, and intestinal juice. A modified method that replaced agar plates with MRS broth was used in the present study (Argyri et al., 2013). The MIC of the 3 tested strains was measured against 9 antibiotics of different groups: cell wall inhibitors (azithromycin, cephalexin, penicillin G, and ampicillin) and protein synthesis inhibitors (kanamycin, streptomycin, tetracycline, chloramphenicol, and roxithromycin). Strains were considered resistant if their MIC values were higher than the MIC breakpoints established by the European Food Safety Authority (EFSA, 2012).

As shown in Table 2, all of the investigated strains were resistant to chloramphenicol, streptomycin, and kanamycin. Strain LHL7 was different from LHL6 and CECT5716, being susceptible to ampicillin and resistant to tetracycline, according to the EFSA cut-off points.

The response of the 3 strains to azithromycin, cephalexin, and penicillin $\mathrm{G}$ was similar, having the same MIC of 20,640 , and $0.64 \mathrm{mg} / \mathrm{L}$, respectively (cut-offs not on the EFSA list). Azithromycin was the most active antibiotic tested against the gram-negative anaerobes (Williams et al., 1992). Compared with a $\mathrm{MIC}_{90}$ against azithromycin ranging from 2.0 to $256 \mathrm{mg} / \mathrm{L}$ to different species of LAB (Weintraub et al., 2016), the 3 strains all showed moderate resistance, with MIC of $20 \mathrm{mg} / \mathrm{L}$. The MIC of the investigated strains against cephalexin was $640 \mathrm{mg} / \mathrm{L}$, showing much higher resistance than either the DSM 20021T strain or Lacticaseibacillus rhamnosus GG (Coppola et al., 2005).

In our study, all 3 strains showed no obvious growth in the presence of $0.64 \mathrm{mg} / \mathrm{L}$ penicillin $\mathrm{G}$ (equal to $1.1 \mathrm{IU} / \mathrm{mL}$ for penicillin containing 1,670 IU/mg; Humphrey et al., 1953). This level was lower than that of the strains screened from human milk $(10 \mathrm{mg} / \mathrm{L}$; Riaz Rajoka et al., 2017) and Lacticaseibacillus casei (Lacto- 
bacillus casei) Shirota from fermented olives ( $8 \mathrm{mg} / \mathrm{L}$; Argyri et al., 2013). Thus, we concluded that the LHL6, LHL7, and CECT5716 strains were all susceptible to penicillin $\mathrm{G}$, which is in line with an earlier report that rod-shaped LAB strains are sensitive to penicillin (Jose et al., 2015).

For roxithromycin, the LHL6 and LHL7 strains (MIC $\leq 0.64 \mathrm{mg} / \mathrm{L})$ were more susceptible than CECT5716 $(\mathrm{MIC}=1.28 \mathrm{mg} / \mathrm{L})$. This may be interpreted as weak susceptibility, because $0.6 \mathrm{mg} / \mathrm{L}$ was selected as the test concentration in several studies (Ali et al., 2017; Tada et al., 2018; Khan et al., 2019).

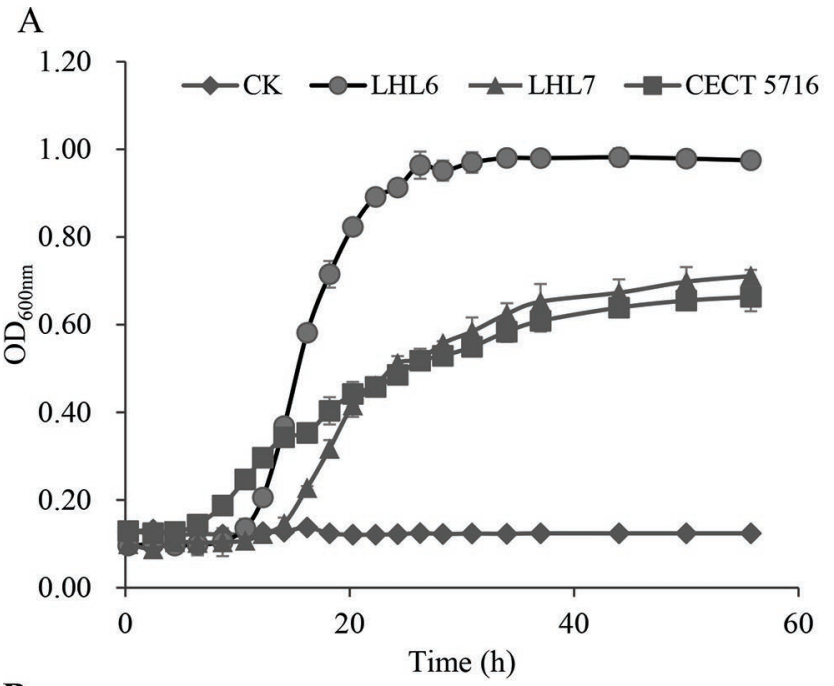

B

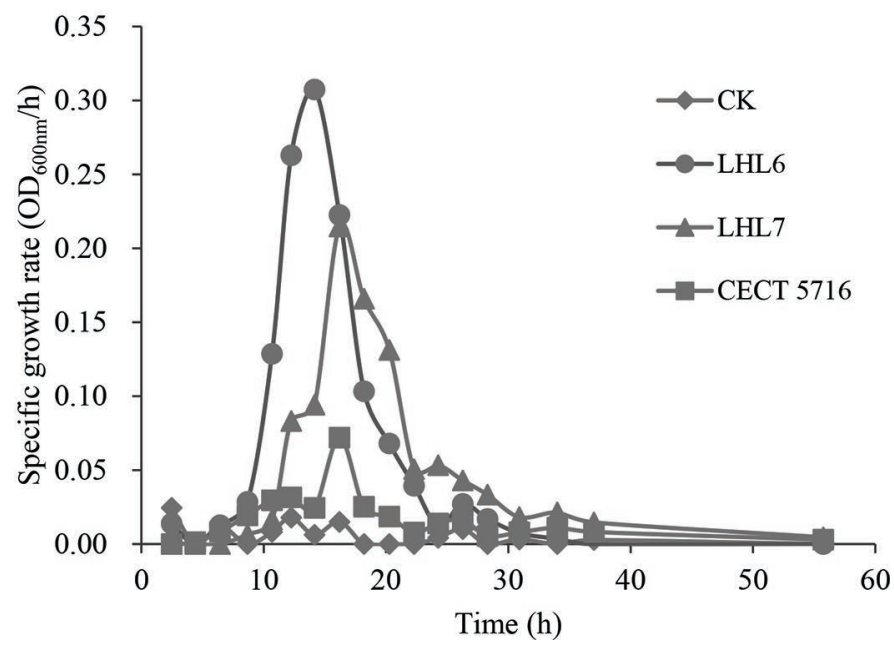

Figure 3. The (A) optical density at $600 \mathrm{~nm}\left(\mathrm{OD}_{600 \mathrm{~mm}}\right)$ of the cultures, and (B) specific growth rate $\left(\mathrm{OD}_{600 \mathrm{~mm}} / \mathrm{h}\right)$ of strains Lacticaseibacillus rhamnosus LHL6, Lacticaseibacillus rhamnosus LHL7, and Limosilactobacillus fermentum CECT5716 in de Man, Rogosa, and Sharpe (MRS) broth at $37^{\circ} \mathrm{C}$ compared with the control (CK, MRS broth). Error bars refer to the SD of the 3 replicates of each assay.
A

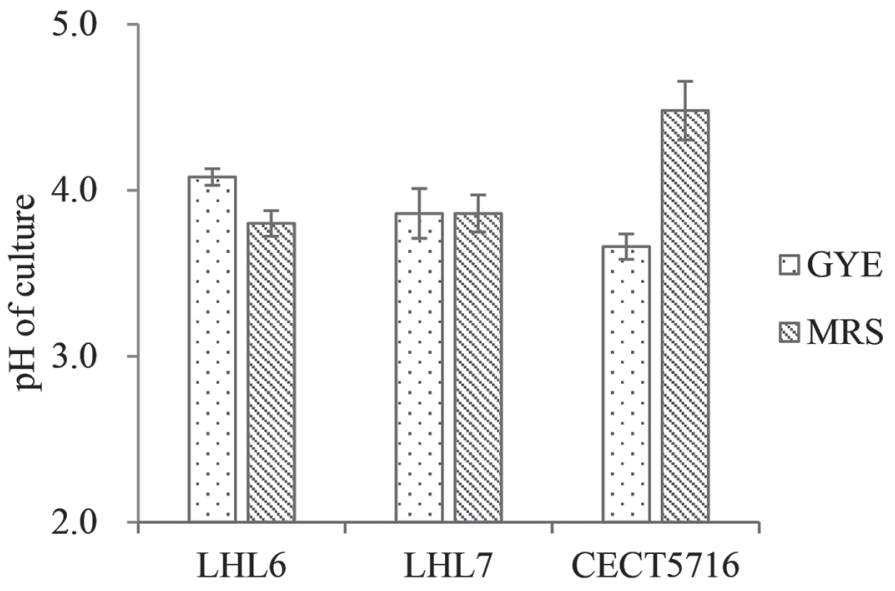

B

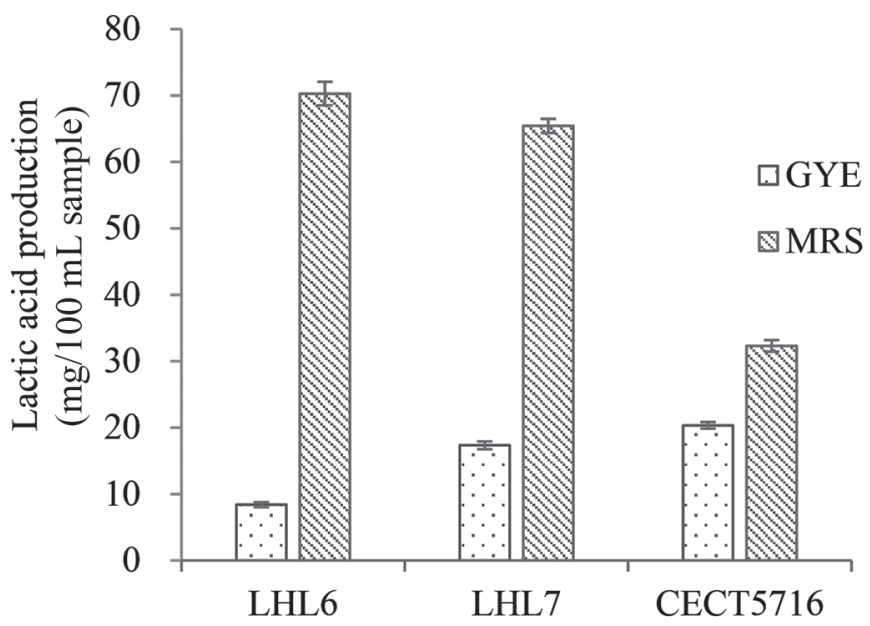

$\mathrm{C}$

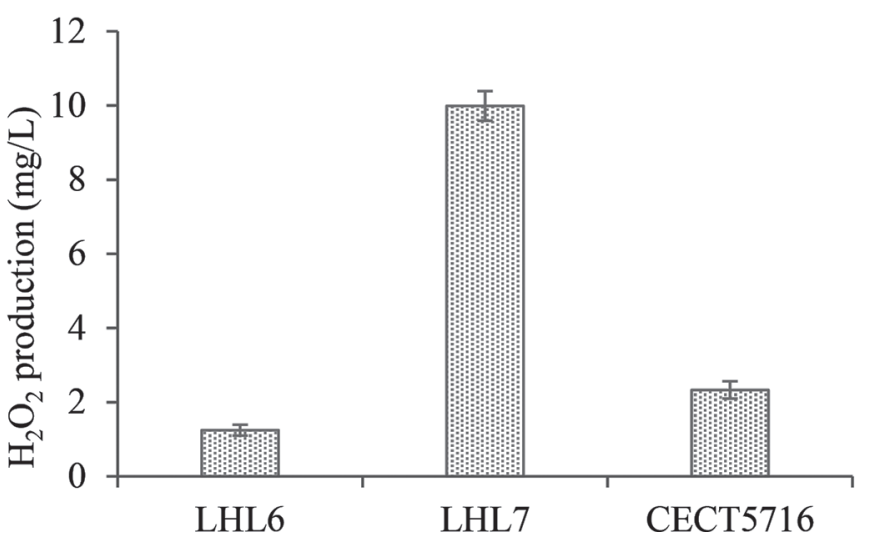

Figure 4. The $\mathrm{pH}$ of cultures (A), lactic acid production (B) at $37^{\circ} \mathrm{C}$ in glucose-yeast extract (GYE) and de Man, Rogosa, and Sharpe (MRS) media, and $\mathrm{H}_{2} \mathrm{O}_{2}$ production $(\mathrm{C})$ at $37^{\circ} \mathrm{C}$ in MRS broth by strains Lacticaseibacillus rhamnosus LHL6, Lacticaseibacillus rhamnosus LHL7, and Limosilactobacillus fermentum CECT5716. Error bars refer to the SD of the 3 replicates of each assay. 
The LHL6 and LHL7 strains exhibited higher sensitivity to several of the tested antibiotics compared with the standard strain CECT5716, whereas all rod-shaped LAB strains were sensitive to ampicillin, cephalexin, penicillin, and streptomycin (Wang et al., 2010). In addition, 2 Levilactobacillus brevis strains were also sensitive to ampicillin, cephalexin, chloramphenicol, spectinomycin, and tetracycline (Rönkä et al., 2003). Conversely, studies have reported antibiotic resistance in some LAB strains, implying that variable antibiotic susceptibility depends upon specific strains (Gheziel et al., 2019).

According to Sharma et al. (2016), antibiotic resistance has two sides. Probiotic strains could have special use if they are antibiotic-resistant. For example, strains resistant to a specific antibiotic can be applied at the time of antibiotic treatment for better recovery of GIT microbiota. Drawbacks of antibiotic resistance are that antibiotic resistance genes may be transferred to other bacteria by means of conjugation, resulting in pathogenic bacteria with high antibiotic resistance (Cebeci and Gürakan, 2003). Researchers have investigated antibiotic resistance genes in LAB. As discussed by Jose et al. (2015), there are 2 types of bacterial resistance to antibiotics: intrinsic (natural) and acquired. Intrinsic resistance is an inherent feature of the bacterial strain, which is known to be chromosomally encoded and not transferable. For instance, the vancomycin resistance of Lacticaseibacillus rhamnosus and Limosilactobacillus reuteri was shown, in several studies, to be intrinsic and chromosomally encoded (Hamilton-Miller and Shah, 1998; Tynkkynen et al., 1998; Vanderhoof et al., 1999; Klein et al., 2000). In contrast, acquired resistance can arise through spontaneous gene mutation or horizontal gene transfer. This could pose a threat of potential gene transfer to other bacteria. For example, a high frequency of resistance to kanamycin and streptomycin was shown to be acquired by spontaneous mutation in rod-shaped LAB strains (Curragh and Collins, 2008). Jose et al. (2015) concluded that antibiotic resistance of rod-shaped LAB was strain dependent and would not be a threat if the resistance genes were not transferable. In our future work, we aim to identify the antibiotic resistance genes in the selected potential probiotic strains.

\section{Survival Under Simulated GIT Conditions}

The survival rate of the strains after exposure to conditions simulating those found in the human GIT varied depending on strains and processes. Table 3 shows the survival percentage of the tested strains at different stages, including at 40,60, 80, and $180 \mathrm{~min}$ after exposure to saliva-like and gastric-like solutions, and subsequently transferred to the intestine-like solution for the following $120 \mathrm{~min}$.

All strains were able to survive under the simulated GIT conditions. Strains LHL6 and LHL7 showed survival rates of 7.13 and $5.74 \%$, respectively, whereas that of CECT5716 was $5.77 \%$. The secretion resembling saliva had no obvious effect on the viability of the strains, which is in accordance with a former report (Martín et al., 2005). The low-pH gastric-like solution killed $\sim 30 \%$ of the cells during the initial $80 \mathrm{~min}$. Finally, less than $10 \%$ of cells survived after the final treatment with simulated intestinal solution for 120 min. The survival rates were much lower than the 30 to $70 \%$ (Lactobacillus gasseri, Lacticaseibacillus casei, and Lacticaseibacillus rhamnosus GG) reported in a previous study (Martín et al., 2005). The survival rate of Lacticaseibacillus rhamnosus Z5 was reported to be $76.14 \%$ (Gao et al., 2017) after incubation for $6 \mathrm{~h}$ in $0.15 \%$ bile salts, but severe inhibition of cells occurred at a higher concentration of bile salt. However, another

Table 2. Minimum inhibitory concentrations of different antibiotics (mg/L) against tested strains: Limosilactobacillus fermentum CECT5716 and Lacticaseibacillus rhamnosus LHL6 and LHL7

\begin{tabular}{llccc}
\hline & & \multicolumn{3}{c}{ Strain $^{1}$} \\
\cline { 2 - 5 } Antibiotic & \begin{tabular}{l} 
MIC breakpoint \\
\cline { 2 - 4 }
\end{tabular} & CECT5 $)$ & LHL6 & LHL7 \\
\hline Azithromycin & $--^{2}$ & $20^{\mathrm{mr}}$ & $20^{\mathrm{mr}}$ & $20^{\mathrm{mr}}$ \\
Cephalexin & 4 & $640^{\mathrm{r}}$ & $640^{\mathrm{r}}$ & $640^{\mathrm{r}}$ \\
Ampicillin & - & $9.6^{\mathrm{r}}$ & $9.6^{\mathrm{r}}$ & $1.28^{\mathrm{r}}$ \\
Penicillin G & 8 & $\leq 0.64^{\mathrm{s}}$ & $\leq 0.64^{\mathrm{s}}$ & $\leq 0.64^{\mathrm{s}}$ \\
Tetracycline & - & $2.48^{\mathrm{s}}$ & $4.8^{\mathrm{s}}$ & $9.6^{\mathrm{r}}$ \\
Roxithromycin & 4 & $1.28^{\mathrm{r}}$ & $\leq 0.64^{\mathrm{s}}$ & $\leq 0.64^{\mathrm{s}}$ \\
Chloramphenicol & 32 & $9.6^{\mathrm{r}}$ & $9.6^{\mathrm{r}}$ & $9.6^{\mathrm{r}}$ \\
Streptomycin & 64 & $320^{\mathrm{r}}$ & $40^{\mathrm{r}}$ & $40^{\mathrm{r}}$ \\
Kanamycin & $1,280^{\mathrm{r}}$ & $320^{\mathrm{r}}$ & $320^{\mathrm{r}}$ \\
\hline
\end{tabular}

${ }^{1}$ Where $\mathrm{s}=$ susceptible; $\mathrm{r}=$ resistant $; \mathrm{mr}=$ moderately resistant.

${ }^{2} \mathrm{MIC}$ breakpoint not provided in EFSA (2012).

${ }^{3}$ For penicillin containing 1,670 IU/mg (Humphrey et al., 1953). 
Table 3. Survival rate of the tested lactic acid bacteria strains under simulated gastrointestinal tract (GIT) conditions $^{1}$

\begin{tabular}{lccccc}
\hline & \multicolumn{5}{c}{ Time (min) } \\
\cline { 2 - 6 } Strain $^{2}$ & 40 & 60 & 80 & 180 & 300 \\
\hline LHL6 & $95.98 \pm 4.95$ & $94.98 \pm 3.96$ & $26.27 \pm 3.33$ & $17.15 \pm 2.01$ & $7.13 \pm 1.03$ \\
LHL7 & $97.31 \pm 3.22$ & $92.81 \pm 3.55$ & $29.06 \pm 2.95$ & $14.72 \pm 2.77$ & $5.74 \pm 1.24$ \\
CECT5716 & $97.81 \pm 5.60$ & $94.51 \pm 5.12$ & $30.64 \pm 1.99$ & $12.10 \pm 2.20$ & $5.77 \pm 2.07$ \\
\hline
\end{tabular}

${ }^{1}$ Data shown are mean \pm SD and indicate the survival percentage of lactic acid bacteria strains inoculated $\left(10^{9}\right.$ $\mathrm{cfu} / \mathrm{mL})$ in fermented milks under simulated human GIT conditions.

${ }^{2}$ Lacticaseibacillus rhamnosus LHL6 and LHL7 and Limosilactobacillus fermentum CECT5716.

study reported that Lacticaseibacillus rhamnosus GG growth was inhibited at $0.15 \%$ bile salts (Zhao et al., 2016). For most studies, survival of LAB was evaluated after a treatment of low $\mathrm{pH}$ or bile salt but not both (Argyri et al., 2013; Liu et al., 2020a), whereas the cells in the current study were treated in in a stepwise manner from saliva to gastric juice and then intestinal juice. In addition, the concentrations of related enzymes were at a relatively high level and cells were exposed for a relatively long duration. This might have influenced the observed low final survival rate. Nevertheless, the LHL6 and LHL7 strains behaved similarly to the reference strain CECT5716, showing weak tolerance to GIT conditions. It is likely that the survival rates of $\mathrm{LAB}$ in infants would be higher, because the environmental conditions found in the infant GIT are generally not as restrictive as those of the adult (Martín et al., 2005). Providing protectants is an alternative method by which to maintain a relatively high level of viability after oral administration (Su et al., 2019).

\section{Cadmium Tolerance and Binding Ability}

The percentage of $\mathrm{Cd}$ removed (bound by bacteria) is frequently used to assess Cd binding ability of bacterial strains. When the initial concentration of $\mathrm{Cd}$ was 50 $\mathrm{mg} / \mathrm{L}$, the Cd removal rate varied from $1.45 \%$ to $4.57 \%$ among the tested strains, and LHL7 demonstrated the maximum removal percentage (Table 4). This observa- tion might indicate that the 3 strains can bind $\mathrm{Cd}$ but with low efficiency, because the percentage removal of 33 LAB ranges from 3.56 to $31.34 \%$, with $18 \%$ as the standard (Zhai et al., 2015).

Tolerance of the tested strains to $\mathrm{Cd}$ was determined by a MIC assay conducted with different initial Cd concentrations. In Table 4, the MIC for all 3 tested strains in MRS broth and on MRS agar plates were greater than 500 and 1,000 mg/L, respectively. The same level of Cd tolerance was reported for the Lactiplantibacillus plantarum ssp. plantarum CCFM8610 strain isolated from fermented pickles (Zhai et al., 2015). This strain is used for the production of yogurt by Bright Dairy and Food Co. Ltd. (Shanghai, China). A previous study showed that Lactobacillus acidophilus had a MIC of 500 $\mathrm{mg} / \mathrm{L} \mathrm{Cd}$ (Ali et al., 2017). Thus, we can conclude that the tested strains had good tolerance to $\mathrm{Cd}$.

With industrial development, $\mathrm{Cd}$ pollution is a serious public health issue, especially in developing countries (Milani et al., 2017). When LAB strains are introduced orally to humans or animals at risk of $\mathrm{Cd}$ exposure, high tolerance to $\mathrm{Cd}$ will enable better survival, and a rapid and effective ability to bind $\mathrm{Cd}$ may allow the strains to bind Cd before intestinal absorption. This benefit will result in an increase in fecal $\mathrm{Cd}$ levels and a decrease in $\mathrm{Cd}$ accumulation in the body (Zhai et al., 2013, 2014, 2016). In this work, the tested strains showed excellent $\mathrm{Cd}$ tolerance with a MIC of $1,000 \mathrm{mg} / \mathrm{L}$ but low $\mathrm{Cd}$ binding of $<10 \%$. As long as

Table 4. Ability of the tested lactic acid bacteria strains to bind and remove cadmium and tolerance to cadmium (tested by MIC assay)

\begin{tabular}{lccc}
\hline & \multicolumn{3}{c}{ Strain $^{1}$} \\
\cline { 2 - 4 } Item & LHL6 & LHL7 & CECT5716 \\
\hline Cd removal rate $^{2}(\%)$ & $1.81 \pm 0.32$ & $4.57 \pm 0.69$ & $4.09 \pm 0.33$ \\
MIC in MRS ${ }^{3}$ broth $(\mathrm{mg} / \mathrm{L})$ & $>500$ & $>500$ & $>500$ \\
MIC on MRS agar $(\mathrm{mg} / \mathrm{L})$ & $>1,000$ & $>1,000$ & $>1,000$ \\
\hline${ }^{1}$ Lacticaseibacillus rhamnosus LHL6 and LHL7 and Limosilactobacillus fermentum CECT5716. \\
${ }^{2}$ Data shown are mean \pm SD. & & \\
${ }^{3}$ de Man, Rogosa, and Sharpe. & &
\end{tabular}


the bacteria are alive, removal of $\mathrm{Cd}$ is possible, even though it is not as optimally efficient.

Advances in the assessment of early hosts and breastfeeding microbes suggest that microorganisms in breast milk benefit human health throughout life. However, studies on currently available strains isolated from human milk are scarce, particularly in China, where most probiotic strains used are imported from Europe and the United States. This is the case with the reference strain Limosilactobacillus fermentum CECT5716. Studies on microbiota from human milk and gut have shown that microbial composition is affected by many factors. Geographic location and dietary pattern are both significant factors (Boix-Amorós et al., 2019; Moossavi et al., 2019). Thus, it has not yet been elucidated whether imported strains are suitable for Chinese metabolism and intestinal physiology. In the present study, 2 potential probiotic strains, LHL6 and LHL7, isolated from human milk of Chinese woman are provided. These strains might be more suitable for Chinese people.

\section{CONCLUSIONS}

Human milk is an excellent source for the isolation of LAB strains, which are frequently used as probiotics. Here, we isolated 2 Lacticaseibacillus rhamnosus strains, LHL6 and LHL7, from breast milk of healthy Chinese women. Their potential as probiotics was evaluated in vitro, using Limosilactobacillus fermentum CECT5716 as the reference strain. Strains LHL6 and LHL7 showed a longer lag phase than the reference strain but grew faster after adaptation. Concerning production of lactic acid and $\mathrm{H}_{2} \mathrm{O}_{2}$, LHL7 performed better than either LHL6 or CECT5716, indicating better antimicrobial ability. Resistance against 9 clinically used antibiotics was strain-dependent. All 3 strains survived a simulated gastric solution, but few survived after exposure to simulated intestinal juice. All strains were able to grow in MRS broth containing $500 \mathrm{mg} / \mathrm{L}$ $\mathrm{Cd}$ and on MRS agar medium supplemented with 1,000 $\mathrm{mg} / \mathrm{L} \mathrm{Cd}$. In summary, the two strains were similar to Limosilactobacillus fermentum CECT5716 for most of the assayed properties. This study revealed the probiotic potential of LAB strains from human milk and provided potential probiotic candidates for application in the food and pharmaceutical industries.

\section{ACKNOWLEDGMENTS}

This work was supported by Ausnutria Probiotic Technology Innovation and Entrepreneurship Team of Hunan Province and Special Innovation Platform of Innovative Province Constructs in Hunan Province (No. 2019TP2066; Hunan, China). We sincerely acknowledge the volunteers who provided breast milk samples. The authors have not stated any conflicts of interest.

\section{REFERENCES}

Abou-Shanab, R. A. I., P. van Berkum, and J. S. Angle. 2007. Heavy metal resistance and genotypic analysis of metal resistance genes in gram-positive and gram-negative bacteria present in Ni-rich serpentine soil and in the rhizosphere of Alyssum murale. Chemosphere 68:360-367. https://doi.org/10.1016/j.chemosphere.2006 .12 .051 .

Ali, N. M., K. Sarwar, S. A. Mazhar, I. Liaqat, S. Andleeb, B. Mazhar, and B. Kalim. 2017. Effect of medicinal plants, heavy metals and antibiotics against pathogenic bacteria isolated from raw, boiled and pasteurized milk. Pak. J. Pharm. Sci. 30:2173-2182.

AOAC. 1990. Official Methods of Analysis. 15th ed. Association of Official Analytical Chemists, Arlington, VA.

Argyri, A. A., G. Zoumpopoulou, K.-A. G. Karatzas, E. Tsakalidou, G.-J. E. Nychas, E. Z. Panagou, and C. C. Tassou. 2013. Selection of potential probiotic lactic acid bacteria from fermented olives by in vitro tests. Food Microbiol. 33:282-291. https://doi.org/10 .1016/j.fm.2012.10.005.

Azad, M. B., T. Konya, H. Maughan, D. S. Guttman, C. J. Field, R. S. Chari, M. R. Sears, A. B. Becker, J. A. Scott, and A. L. Kozyrskyj. 2013. Gut microbiota of healthy Canadian infants: Profiles by mode of delivery and infant diet at 4 months. CMAJ 185:385-394. https://doi.org/10.1503/cmaj.121189.

Boix-Amorós, A., F. Puente-Sanchez, E. du Toit, K. M. Linderborg, Y. Zhang, B. Yang, S. Salminen, E. Isolauri, J. Tamames, A. Mira, and M. C. Collado. 2019. Mycobiome profiles in breast milk from healthy women depend on mode of delivery, geographic location, and interaction with bacteria. Appl. Environ. Microbiol. 85:e02994-18. https://doi.org/10.1128/AEM.02994-18.

Cebeci, A., and C. Gürakan. 2003. Properties of potential probiotic Lactobacillus plantarum strains. Food Microbiol. 20:511-518. https://doi.org/10.1016/S0740-0020(02)00174-0.

Charteris, W. P., P. M. Kelly, L. Morelli, and J. K. Collins. 1998. Antibiotic susceptibility of potentially probiotic Lactobacillus species. J. Food Prot. 61:1636-1643. https://doi.org/10.4315/0362-028X -61.12 .1636 .

Coppola, R., M. Succi, P. Tremonte, A. Reale, G. Salzano, and E. Sorrentino. 2005. Antibiotic susceptibility of Lactobacillus rhamnosus strains isolated from Parmigiano Reggiano cheese. Lait 85:193204. https://doi.org/10.1051/lait:2005007.

Curragh, H., and M. A. Collins. 2008. High levels of spontaneous drug resistance in Lactobacillus. J. Appl. Microbiol. 73:31-36. https:// doi.org/10.1111/j.1365-2672.1992.tb04965.x.

Ding, W., C. Shi, M. Chen, J. Zhou, R. Long, and X. Guo. 2017. Screening for lactic acid bacteria in traditional fermented Tibetan yak milk and evaluating their probiotic and cholesterol-lowering potentials in rats fed a high-cholesterol diet. J. Funct. Foods 32:324-332. https://doi.org/10.1016/j.jff.2017.03.021.

EFSA (European Food Safety Authority). 2012. Guidance on the assessment of bacterial susceptibility to antimicrobials of human and veterinary importance. EFSA J. 10:2740. https://doi.org/10.2903/ j.efsa.2012.2740.

Gao, S., Y. Qiao, Y.-W. Zhang, Q. Peng, Z.-S. Zhang, B. Shi, J.-M. Li, and Y. Wu. 2017. Isolation, identification and probiotic characterization of lactic acid bacteria in human breast milk. Sci. Technol. Food Ind. 38:205-210. [in Chinese]

Gheziel, C., P. Russo, M. P. Arena, G. Spano, H.-I. Ouzari, O. Kheroua, D. Saidi, D. Fiocco, H. Kaddouri, and V. Capozzi. 2019. Evaluating the probiotic potential of Lactobacillus plantarum strains from Algerian infant feces: Towards the design of probiotic starter cultures tailored for developing countries. Probiotics Antimicrob. Proteins 11:113-123. https://doi.org/10.1007/s12602-018-9396-9.

Gil-Campos, M., M. A. Lopez, M. V. Rodriguez-Benitez, J. Romero, I. Roncero, M. D. Linares, J. Maldonado, E. Lopez-Huertas, R. Berwind, K. L. Ritzenthaler, V. Navas, C. Sierra, L. Sempere, A. Geerlings, J. A. Maldonado-Lobon, A. D. Valero, F. Lara-Villosla- 
da, and M. Olivares. 2012. Lactobacillus fermentum CECT 5716 is safe and well tolerated in infants of 1-6 months of age: A randomized controlled trial. Pharmacol. Res. 65:231-238. https://doi.org/ 10.1016/j.phrs.2011.11.016.

Gilliland, S. E. 1969. Enzymatic determination of residual hydrogen peroxide in milk. J. Dairy Sci. 52:321-324. https://doi.org/10 .3168/jds.S0022-0302(69)86554-9.

Guaraldi, F., and G. Salvatori. 2012. Effect of breast and formula feeding on gut microbiota shaping in newborns. Front. Cell. Infect. Microbiol. 2:94. https://doi.org/10.3389/fcimb.2012.00094.

Hamilton-Miller, J. M., and S. Shah. 1998. Vancomycin susceptibility as an aid to the identification of lactobacilli. Lett. Appl. Microbiol. 26:153-154. https://doi.org/10.1046/j.1472-765X.1998.00297.x.

Huddleston, J. R. 2014. Horizontal gene transfer in the human gastrointestinal tract: potential spread of antibiotic resistance genes. Infect. Drug Resist. 7:167-176. https://doi.org/10.2147/IDR.S48820.

Humphrey, J. H., M. V. Musset, and W. L. Perry. 1953. The second international standard for penicillin. Bull. World Health Organ. 9:15-28.

Jiang, M., F. Zhang, C. Wan, Y. Xiong, N. P. Shah, H. Wei, and X. Tao. 2016. Evaluation of probiotic properties of Lactobacillus plantarum WLPL04 isolated from human breast milk. J. Dairy Sci. 99:1736-1746. https://doi.org/10.3168/jds.2015-10434.

Jiang, Y., N. Li, Q. Wang, Z. Liu, Y.-K. Lee, X. Liu, J. Zhao, H. Zhang, and W. Chen. 2020. Microbial diversity and volatile profile of traditional fermented yak milk. J. Dairy Sci. 103:87-97. https:/ /doi.org/10.3168/jds.2019-16753.

Jose, N. M., C. R. Bunt, and M. A. Hussain. 2015. Implications of antibiotic resistance in probiotics. Food Rev. Int. 31:52-62. https: //doi.org/10.1080/87559129.2014.961075.

Khan, U., S. Afsana, M. Kibtia, M. Hossain, N. Choudhury, and C. R. Ahsan. 2019. Presence of blaCTX-M antibiotic resistance gene in Lactobacillus spp. isolated from Hirschsprung diseased infants with stoma. J. Infect. Dev. Ctries. 13:426-433. https://doi.org/10 $.3855 /$ jidc. 10968 .

Klein, G., C. Hallmann, I. A. Casas, J. Abad, J. Louwers, and G. Reuter. 2000. Exclusion of vanA, vanB and vanC type glycopeptide resistance in strains of Lactobacillus reuteri and Lactobacillus rhamnosus used as probiotics by polymerase chain reaction and hybridization methods. J. Appl. Microbiol. 89:815-824. https:// doi.org/10.1046/j.1365-2672.2000.01187.x.

Kuznetsov, A., A. Beloded, A. Derunets, V. Grosheva, L. Vakar, R. Kozlovskiy, and V. Shvets. 2017. Biosynthesis of lactic acid in a membrane bioreactor for cleaner technology of polylactide production. Clean Technol. Environ. Policy 19:869-882. https://doi.org/ 10.1007/s10098-016-1275-z.

Langa, S., A. Maldonado-Barragan, S. Delgado, R. Martin, V. Martin, E. Jimenez, J. L. Ruiz-Barba, B. Mayo, R. I. Connor, J. E. Suarez, and J. M. Rodriguez. 2012. Characterization of Lactobacillus salivarius CECT 5713, a strain isolated from human milk: from genotype to phenotype. Appl. Microbiol. Biotechnol. 94:1279-1287. https://doi.org/10.1007/s00253-012-4032-1.

Lavilla-Lerma, L., R. Pérezpulido, M. Martínezbueno, M. Maqueda, and E. Valdivia. 2013. Characterization of functional, safety, and gut survival related characteristics of Lactobacillus strains isolated from farmhouse goat's milk cheeses. Int. J. Food Microbiol. 163:136-145. https://doi.org/10.1016/j.ijfoodmicro.2013.02.015.

Li, N., B. Pang, G. Liu, X. Zhao, X. Xu, C. Jiang, B. Yang, Y. Liu, and J. Shi. 2020. Lactobacillus rhamnosus from human breast milk shows therapeutic function against foodborne infection by multidrug resistant Escherichia coli in mice. Food Funct. 11:435-447. https://doi.org/10.1039/c9fo01698h.

Li, S. W., K. Watanabe, C. C. Hsu, S. H. Chao, Z. H. Yang, Y. J. Lin, C. C. Chen, Y. M. Cao, H. C. Huang, C. H. Chang, and Y.-C. Tsai. 2017. Bacterial composition and diversity in breast milk samples from mothers living in Taiwan and mainland China. Front. Microbiol. 8:965. https://doi.org/10.3389/fmicb.2017.00965.

Liu, W., M. Chen, L. Duo, J. Wang, S. Guo, H. Sun, B. Menghe, and H. Zhang. 2020a. Characterization of potentially probiotic lactic acid bacteria and bifidobacteria isolated from human colostrum. J. Dairy Sci. 103:4013-4025. https://doi.org/10.3168/jds.2019-17602.
Liu, Z., A. Subbaraj, K. Fraser, H. Jia, W. Chen, L. Day, N. C. Roy, and W. Young. 2020b. Human milk and infant formula differentially alters the microbiota composition and functional gene relative abundance in the small and large intestines in weanling rats. Eur. J. Nutr. https://doi.org/10.1007/s00394-019-02062-w.

Marteau, P., M. Minekus, R. Havenaar, and J. H. J. Huis In't Veld. 1997. Survival of lactic acid bacteria in a dynamic model of the stomach and small intestine: validation and the effects of bile. J. Dairy Sci. 80:1031-1037. https://doi.org/10.3168/jds.S0022 $-0302(97) 76027-2$.

Martín, R., S. Langa, C. Reviriego, E. Jimínez, M. L. Marín, J. Xaus, L. Fernández, and J. M. Rodríguez. 2003. Human milk is a source of lactic acid bacteria for the infant gut. J. Pediatr. 143:754-758. https://doi.org/10.1016/j.jpeds.2003.09.028.

Martín, R., M. Olivares, M. L. Marín, L. Fernández, J. Xaus, and J. M. Rodríguez. 2005. Probiotic potential of 3 lactobacilli strains isolated from breast milk. J. Hum. Lact. 21:8-17. https://doi.org/ 10.1177/0890334404272393.

Matyar, F., A. Kaya, and S. Dinçer. 2008. Antibacterial agents and heavy metal resistance in Gram-negative bacteria isolated from seawater, shrimp and sediment in Iskenderun Bay, Turkey. Sci. Total Environ. 407:279-285. https://doi.org/10.1016/j.scitotenv 2008.08.014.

McGuire, M. K., and M. A. McGuire. 2015. Human milk: Mother nature's prototypical probiotic food? Adv. Nutr. 6:112-123. https:// doi.org/10.3945/an.114.007435.

Milani, C., S. Duranti, F. Bottacini, E. Casey, F. Turroni, J. Mahony, C. Belzer, S. Delgado Palacio, S. Arboleya Montes, L. Mancabelli, G. A. Lugli, J. M. Rodriguez, L. Bode, W. de Vos, M. Gueimonde, A. Margolles, D. van Sinderen, and M. Ventura. 2017. The first microbial colonizers of the human gut: Composition, activities, and health implications of the infant gut microbiota. Microbiol. Mol. Biol. Rev. 81:e00036-17. https://doi.org/10.1128/MMBR .00036-17.

Moossavi, S., and M. B. Azad. 2019. Origins of human milk microbiota: New evidence and arising questions. Gut Microbes https:// doi.org/10.1080/19490976.2019.1667722.

Moossavi, S., S. Sepehri, B. Robertson, L. Bode, S. Goruk, C. J. Field, L. M. Lix, R. J. de Souza, A. B. Becker, P. J. Mandhane, S. E. Turvey, P. Subbarao, T. J. Moraes, D. L. Lefebvre, M. R. Sears, E. Khafipour, and M. B. Azad. 2019. Composition and variation of the human milk microbiota are influenced by maternal and earlylife factors. Cell Host Microbe 25:324-335.e4. https://doi.org/10 .1016/j.chom.2019.01.011.

Mueller, N. T., E. Bakacs, J. Combellick, Z. Grigoryan, and M. G. Dominguez-Bello. 2015. The infant microbiome development: mom matters. Trends Mol. Med. 21:109-117. https://doi.org/10.1016/j .molmed.2014.12.002.

NHC-PRC (National Health Commission of the People's Republic of China). 2016. Announcement on three strains including Limosilactobacillus fermentum CECT5716. Vol. 2016. http://www.nhc.gov .cn/sps/s7891/201606/3ea5182360de4ac48ff44de1698f9932.shtml.

Oikonomou, G., M. F. Addis, C. Chassard, M. E. F. Nader-Macias, I. Grant, C. Delbès, C. I. Bogni, Y. Le Loir, and S. Even. 2020. Milk microbiota: What are we exactly talking about? Front. Microbiol. 11:60. https://doi.org/10.3389/fmicb.2020.00060.

Ojo-Okunola, A., M. Nicol, and E. du Toit. 2018. Human breast milk bacteriome in health and disease. Nutrients 10:1643. https://doi .org/10.3390/nu10111643.

Pannaraj, P. S., F. Li, C. Cerini, J. M. Bender, S. Yang, A. Rollie, H. Adisetiyo, S. Zabih, P. J. Lincez, K. Bittinger, A. Bailey, F. D. Bushman, J. W. Sleasman, and G. M. Aldrovandi. 2017. Association between breast milk bacterial communities and establishment and development of the infant gut microbiome. JAMA Pediatr. 171:647-654. https://doi.org/10.1001/jamapediatrics.2017.0378.

Riaz Rajoka, M. S., H. M. Mehwish, M. Siddiq, Z. Haobin, J. Zhu, L. Yan, D. Shao, X. Xu, and J. Shi. 2017. Identification, characterization, and probiotic potential of Lactobacillus rhamnosus isolated from human milk. Lebensm. Wiss. Technol. 84:271-280. https:// doi.org/10.1016/j.lwt.2017.05.055. 
Rönkä, E., E. Malinen, M. Saarela, M. Rinta-Koski, J. Aarnikunnas, and A. Palva. 2003. Probiotic and milk technological properties of Lactobacillus brevis. Int. J. Food Microbiol. 83:63-74. https://doi .org/10.1016/S0168-1605(02)00315-X.

Sharma, P., S. K. Tomar, V. Sangwan, P. Goswami, and R. Singh. 2016. Antibiotic resistance of Lactobacillus sp. isolated from commercial probiotic preparations. J. Food Saf. 36:38-51. https://doi .org $/ 10.1111 /$ jfs. 12211

Su, Y., X. Zheng, Q. Zhao, N. Fu, H. Xiong, W. D. Wu, and X. D. Chen. 2019. Spray drying of Lactobacillus rhamnosus GG with calcium-containing protectant for enhanced viability. Powder Technol. 358:87-94. https://doi.org/10.1016/j.powtec.2018.09.082.

Tada, H., C. Masaki, S. Tsuka, T. Mukaibo, Y. Kondo, and R. Hosokawa. 2018. The effects of Lactobacillus reuteri probiotics combined with azithromycin on peri-implantitis: A randomized placebo-controlled study. J. Prosthodont. Res. 62:89-96. https://doi.org/10 .1016/j.jpor.2017.06.006.

Tynkkynen, S., K. V. Singh, and P. Varmanen. 1998. Vancomycin resistance factor of Lactobacillus rhamnosus GG in relation to enterococcal vancomycin resistance (van) genes. Int. J. Food Microbiol. 41:195-204. https://doi.org/10.1016/S0168-1605(98)00051-8.

Vanderhoof, J. A., D. B. Whitney, D. L. Antonson, T. L. Hanner, J. V. Lupo, and R. J. Young. 1999. Lactobacillus GG in the prevention of antibiotic-associated diarrhea in children. J. Pediatr. 135:564568. https://doi.org/10.1016/S0022-3476(99)70053-3.

Wang, C.-Y., P.-R. Lin, C.-C. Ng, and Y.-T. Shyu. 2010. Probiotic properties of Lactobacillus strains isolated from the feces of breastfed infants and Taiwanese pickled cabbage. Anaerobe 16:578-585. https://doi.org/10.1016/j.anaerobe.2010.10.003.

Wang, Z., J. Li, Y. Zhu, S. Zheng, Z. Qiao, W. Zhang, and H. Li. 2019. Isolation, identification and characterization of high yield acid-producing lactic acid bacteria from traditionally fermented soy-whey. China Brewing 38:14-19. [in Chinese]

Weintraub, A., M.-U. Rashid, and C. E. Nord. 2016. In vitro activity of solithromycin against anaerobic bacteria from the normal intestinal microbiota. Anaerobe 42:119-122. https://doi.org/10.1016/j .anaerobe.2016.10.002.

Williams, J. D., J. P. Maskell, H. Shain, G. Chrysos, A. M. Sefton, H. Y. Fraser, and J. M. Hardie. 1992. Comparative in vitro activity of azithromycin, macrolides (erythromycin, clarithromycin and spiramycin) and streptogramin RP 59500 against oral organisms. J. Antimicrob. Chemother. 30:27-37. https://doi.org/10.1093/jac/ 30.1.27.

Williams, J. E., J. M. Carrothers, K. A. Lackey, N. F. Beatty, S. L. Brooker, H. K. Peterson, K. M. Steinkamp, M. A. York, B. Shafii, W. J. Price, M. A. McGuire, and M. K. McGuire. 2019. Strong multivariate relations exist among milk, oral, and fecal microbi- omes in mother-infant dyads during the first six months postpartum. J. Nutr. 149:902-914. https://doi.org/10.1093/jn/nxy299.

Yin, R., Q. Zhai, L. Yu, Y. Xiao, G. Wang, R. Yu, F. Tian, and W. Chen. 2016. The binding characters study of lead removal by Lactobacillus plantarum CCFM8661. Eur. Food Res. Technol. 242:1621-1629. https://doi.org/10.1007/s00217-016-2661-9.

Zhai, Q., F. Tian, J. Zhao, H. Zhang, A. Narbad, and W. Chen. 2016. Oral administration of probiotics inhibits absorption of the heavy metal cadmium by protecting the intestinal barrier. Appl. Environ. Microbiol. 82:4429-4440. https://doi.org/10.1128/AEM.00695-16.

Zhai, Q., G. Wang, J. Zhao, X. Liu, A. Narbad, Y. Q. Chen, H. Zhang, F. Tian, and W. Chen. 2014. Protective effects of Lactobacillus plantarum CCFM8610 against chronic cadmium toxicity in mice indicate routes of protection besides intestinal sequestration. Appl. Environ. Microbiol. 80:4063-4071. https://doi.org/10.1128/AEM .00762-14.

Zhai, Q., G. Wang, J. Zhao, X. Liu, F. Tian, H. Zhang, and W. Chen. 2013. Protective effects of Lactobacillus plantarum CCFM8610 against acute cadmium toxicity in mice. Appl. Environ. Microbiol. 79:1508-1515. https://doi.org/10.1128/AEM.03417-12.

Zhai, Q., R. Yin, L. Yu, G. Wang, F. Tian, R. Yu, J. Zhao, X. Liu, Y. Q. Chen, H. Zhang, and W. Chen. 2015. Screening of lactic acid bacteria with potential protective effects against cadmium toxicity. Food Control 54:23-30. https://doi.org/10.1016/j.foodcont .2015.01.037.

Zhao, F., L. I. Yan-Qin, and L. I. Bin-Chun. 2016. Screening of probiotic Lactobacillus in simulated gastrointestinal environment. Microbiology China 43:1396-1403. https://doi.org/10.13344/j .microbiol.china.150898. [in Chinese]

Zimmermann, P., and N. Curtis. 2020. Breast milk microbiota: A review of the factors that influence composition. J. Infect. https:// doi.org/10.1016/j.jinf.2020.01.023.

\section{ORCIDS}

Wenli Kang () https://orcid.org/0000-0002-7345-5079

Lina Pan (1) https://orcid.org/0000-0001-8839-2923

Can Peng ( $\odot$ https://orcid.org/0000-0002-7905-2414

Ling Dong @ https://orcid.org/0000-0001-9266-176X

Sufang Cao ๑ https://orcid.org/0000-0003-1680-4786

Yuguang Wang @ https://orcid.org/0000-0003-1984-066X

Chenchen Zhang () https://orcid.org/0000-0001-8563-5002

Ruixia Gu ๑ https://orcid.org/0000-0002-6186-4318

Jiaqi Wang $\odot$ https://orcid.org/0000-0003-2061-8687

Hongbo Zhou @ (๖) https://orcid.org/0000-0001-6938-3650 